\title{
CLASSROOM MANAGEMENT IN CROSS - CULTURAL CONTEXT
}

\author{
Svetlana Iljjina \\ Rēzeknes Augstskola
}

\begin{abstract}
The subject to be discussed in the present article is classroom management in cross-cultural context. The main reason for the choice of this particular choice was determined mostly by the necessity of varying English language teachers' management skills and teaching techniques in a mixed linguistic classroom. The aim of the research is to explore the ways of improving classroom management skills in a cross-cultural context.
\end{abstract}

Key words: cross-cultural setting, multicultural, management, classroom, communication, facilitator, culture.

\section{Introduction}

The present research investigates the ways of improving classroom management skills paying particular attention to organising efficient and effective English language classrooms for learners of diverse cultural backgrounds. The reason for the choice of the present theme was determined by the necessity of adjusting teaching techniques and management skills to well-planned and well-organised English language classes in the context of cultural diversity at the tertiary level. An increasing number of international students from Asia and Europe encourage language teachers to adapt their language classes to differences in language learning styles across cultures.

The method of research is ethnography and also a case study. The following instruments of research have been applied: analysis of students' written and oral presentations, classroom observation, and group discussion. This is an initial stage of the research based on the author's personal observations and studies. As the following research is long-lasting and requires profound theoretical and practical background, the investigation of the issue will have further examination.

\section{Discussion and Results}

To facilitate the language study in a multicultural classroom it is of paramount importance to improve the organisation of the classroom procedures. The effectiveness of learning process fully depends on high expectations of both teacher and students from learning, positive personal interactions between the students and the teacher, the teacher's clear and efficient instructions, and appreciation of students' progress to promote their motivation and challenge for study (Nunan \& Lamb, 1996:117).

T.Woodward (1991:51) presents a detailed picture of classroom management components. They include:

- preparation and planning; 
- clear instructions and lesson delivery;

- managing students' work;

- anticipating students' and classroom problems;

- classroom arrangement;

- teacher's personality;

- considering and handling teaching aids and equipment;

- giving appropriate feedback.

Among various aspects of classroom management, the inarguable role of a teacher as an effective manager is highlighted, since this is the only prerequisite to successful organisation of classroom work.

Working in a multicultural setting, the teacher should be skilful at managing classroom constraints like large, mixed ability classes, an examination-oriented curriculum, no sources of common interesting reading material in the school library for the entire class, and the like. A properly organised learning process is likely to be the product of successful accomplishment of management objectives and co-operation between the learners and the teacher. The teacher's enthusiasm and skill greatly influence the learners' attitude to the language study. The teacher is responsible for the positive working environment where it is safe for students to make mistakes, ask questions, express their opinions, and where their personal efforts will be recognised and directly rewarded.

The role of the teacher also includes the relationship with the students and managing a number of unpredictable situations in the classroom.

Some of the latest considerations over the place of classroom management are based on the relationships between the teacher and the students. The mutual respect establishes the rapport between the teacher and the students, which ensures a professional approach to teaching a language and class organisation. The efficient techniques applied naturally and consciously in the area of classroom management will lead to well-organized and lively classes.

Apart from being a manager, an instructor, and a facilitator in the classroom, the teacher in a cross-cultural setting has to become a negotiator between two cultures. In this setting, the teacher should observe a good deal before making a decision about the teaching procedure. It is crucial to appraise the cultural identity of a new culture in a class. To prevent any sort of misunderstanding and predicament in the communication and relationship among students, the teacher has to promote additional description and interpretation of daily customs.

Accepting a new culture means recognition of new norms, rules and traditions in a native environment.

The teacher as prompter encourages students to participate in an activity giving concrete suggestions how to perform the task when the students are confused about what to do. Additional instructions are necessary for those activities that seem new and unfamiliar for the students that have not done them in their home learning environment, whereas the rest of the students might be aware of the procedure of the customary activities in their language classes. 
The teacher's role as participant is to be involved in the activities to improve the atmosphere in the classroom and to give the students a chance to communicate with someone who has better knowledge of the language. In addition, cooperating with peers from different cultures, students train their abilities to communicate with a new culture, accept and appreciate a new culture, practice understanding different pronunciation techniques, and learn information about the new culture. Realizing the task, the teacher becomes also a resource being ready to offer any necessary information or help when the students might need it. Being somewhat confused about the correctness of the activity, students from another culture might feel awkward performing the task differently from the rest of the group.

To plan more effective lessons, teachers should consider the content that is to be taught, themes, cultural context, functional tasks, and vocabulary. These main variables should be considered while planning practice activities that involve all students actively during the class work. Teaching a multicultural group of students, the content of the class should be carefully selected. It must be free from any biased viewpoint humiliating any typical features of one or another culture. The theme should be emotively neutral in terms of the attitude towards either of the cultures. Differences in the world perception and the ability to read 'between the lines' may affect the comprehension of a suggested discourse. As a result, misunderstanding or misinterpretation of events or feelings described in literary works may occur due to particular cultural differences. Therefore, this is the teacher's role to define characteristic features of a guest culture to successfully incorporate it into the native culture. Establishing a link between the cultures will only facilitate the learning process and terminate the 'culture' gap in the class.

J. Harmer (2001:308) emphasizes that it is essential to decide what kind of activity would be best for the particular group of students at a particular stage of a lesson. By doing this we will balance the exercises in the lesson that will better engage and motivate the students. At this stage the teacher has to focus on a variety of activities deciding what group arrangements (group work, pair work, individual work, and whole-class discussion) will suit each activity.

To promote effective collaboration among peer-students in the classroom, the teacher should evaluate the abilities and personal characteristics of the students paying attention to cultural peculiarities. The teacher should equally share his/her attention among the students in the entire group. Feeling the lack of the instructor's attention guest students may feel unimportant or invisible in the group. Similarly, native students are likely to feel the same lack of the teacher's attention because of the foreign students in the group.

Teachers will be in a much better position in the lesson if they try to identify problems before they might occur. It is a good idea to anticipate problems that can affect the lesson. The teacher must be ready to adapt his/her lesson plan according to the concrete circumstances, such as: 
- the students take longer or shorter time doing the activity;

- they find the activity easier or more difficult;

- some students finish before the others;

- some students might need extra help;

- some students might be familiar with the material given at the lesson, which will provoke boredom;

- clear, precise and accurate instructions are frequently necessary, especially for guest culture students as they are not accustomed to doing particular activities in the classroom, and they may not know the system of education in a host country.

The author's own experience shows that there might be many more cases when the teacher has to be flexible. Experienced teachers are more skilful at anticipating possible problems within a class period than trainee teachers. Therefore, mentors and/or methodologists ought to share their experience, outlining various cases they have encountered.

Proceeding to effective cross-cultural communication as another part of effective class organization we will discuss the role of teacher talk in particular within the learning process. The ability of the teacher to communicate clearly and impartially is an essential component of effective teaching in a crosscultural context. The teacher's language is supposed to be one of the most important variables in teaching process.

Teachers should eliminate vague and ambiguous words and phrases in the communication with their students. Moreover, separate words or expressions that are accidentally misused or mispronounced may cause confusion and misunderstanding in diverse culture groups. The use of humour and irony imply different connotations in different cultures.

A connected discourse and clear transition signals throughout the teacher's presentation also contribute to the clarity of teacher talk during a lesson. A transition signal ensures the end and beginning of ideas and the link between them as well.

Language learning processes are significantly influenced by the way a classroom is organized. When organizing a class the teacher has to consider the following subjects of particular attention:

- an individual student

- groupings of students

- the class as a whole.

A highly student-centred classroom ensures working individually or in pairs and small groups. This increases student opportunities to perform the target language, increases one's personal sense of relevance and achievement. Working in groups, students learn better from one another rather than from passive listening to a teacher talking. Teachers are supposed to reduce the dominance over activities and tasks, however, they should be prepared for any 
guidance the students might need. Therefore, the most effective learning style in a multicultural classroom organisation is pair and group work.

Group work seems to be an extremely attractive idea for several reasons:

1) It increases the amount of student talking time.

2) It provides more opportunities to use the language to communicate with each other, as well as co-operate.

3) It also ensures a more relaxed atmosphere in a classroom that facilitates problem-solving processes.

4) It makes a prime emphasis on co-operative learning that provides students with more motivation and encouragement resulting in accomplishing the task.

Pair work, as well as group work, can bring more variety into classroom work. Pair work seems to increase the amount of student practice, it allows the students to use language productively, and also encourages student co-operation that is essential for the class atmosphere and motivation.

It is obvious that, when organising pair or group work, the teacher, firstly, is responsible for giving clear and precise instructions about what the students are supposed to do. Secondly, the teacher should listen and offer help where needed. The teacher should certainly spend equal amount of time on different pairs or groups not showing direct preferences to one or another grouping.

\section{Conclusions}

To summarize what has been discussed above, we may conclude that some management techniques need to be improved to eliminate some shortcomings of lessons conducted in a cross-cultural setting. Here are the main drawbacks of the lessons that the author has experienced.

- The teacher may want to use his/her mother tongue on some occasions. Although the majority of the instructions can be formulated in the target language, the teacher occasionally distorts the balance between the target and native language. Consequently, there are several ways to avoid translating words for the learners. Here, synonyms, antonyms, examples, gestures, body language, and facial expressions may be effective in transmitting meanings and showing students that there is no need to know a word in their native language in order to understand the message that is being conveyed. Moreover, it creates an authentic atmosphere where the students are encouraged to take efforts to understand a word or a sentence.

- The students ask too many questions for more additional explanations of the tasks. It proves the fact that the instructions are not properly prepared. As a result, the activities are time-consuming and take more class time than it has been planned.

- While working independently, the students need more assistance on the part of the teacher that proves insufficiency of clear instructions provided for the class. 
- Some of the students remain passive either because of their shyness or low language ability. A whole-class discussion presupposes active involvement of all the students in a class. Unfortunately, only some particular students participate in the discussions, the rest of them remain passive listeners.

- There is rather low involvement in the class work due to the fact that the peer listening to one another is frequently disrupted.

- After class feedback is very important. Moreover, criticism should be very well-grounded and justified. Positive appreciation of progress and the work during a class is ultimately crucial.

This study was undertaken to investigate the ways of improving teachers' classroom management skills and prove that paying particular attention to the cross-cultural differences is crucial in organizing effective teaching and learning in the multicultural language classroom. It is apparent that well-planned and well-managed lessons raise the effectiveness of the learning process. The author of the research strongly believes that a teacher must plan a lesson thoroughly considering different learning styles, exploit the teaching techniques and activities efficiently, manage the classroom procedures and the time successfully, and only then the learners from other cultural backgrounds become active participants in the classroom events and get well-structured knowledge and encouragement to learn the language.

\section{References}

1. Chaudron, C. (1988). Second Language Classrooms. Cambridge: CUP.

2. Farrell, T.S.C. (2002). Lesson Planning, in J.C. Richards, W.A. Renandya (eds), Methodology in Language Teaching. Cambridge: CUP.

3. Gower, R., Phillips, D., Walters, S. (1995). Teaching Practice Handbook. Oxford: Heinemann.

4. Harmer, J. (2001). The Practice of English Language Teaching. London: Longman.

5. Nunan, D., Lamb, C. (1996). The Self-Directed Teacher. Cambridge: CUP.

6. Woodward, T. (1991). Models and Metaphors in Language Teacher Training. Cambridge: CUP.

7. Садохин А. П. (2010). Введение в межкультурную коммуникацию. 2 изд. Москва: Омега-Л. 